\title{
What about the children? The experience of families involved in an adult-focused diabetes intervention
}

\author{
Helena H Laroche $e^{1,2, *}$, Matthew M Davis ${ }^{3,4}$, Jane Forman ${ }^{5}$, Gloria Palmisano ${ }^{6}$ and \\ Michele Heisler ${ }^{3,5,7}$ \\ 'Division of General Medicine, Department of Internal Medicine, University of lowa, VA Medical Center \\ mailstop 152, 601 Highway 6 West, lowa City, IA 52246, USA: ²Division of General Pediatrics, Department \\ of Pediatrics, University of lowa, lowa City, IA, USA: ${ }^{3}$ Division of General Medicine, Department of Internal \\ Medicine, University of Michigan, Ann Arbor, MI, USA: ${ }^{4}$ Child Health Evaluation and Research Unit, \\ Department of Pediatrics, University of Michigan, Ann Arbor, MI, USA: ${ }^{5}$ Center for Practice Management and \\ Outcomes Research, Health Services Research and Development (HSR\&D), Ann Arbor Veterans Affairs Medical \\ Center, Ann Arbor, MI, USA: ${ }^{6}$ Community Health \& Social Services (CHASS) Center, Inc., REACH Detroit \\ Partnership, Detroit, MI, USA: ${ }^{7}$ Michigan Diabetes Research and Training Center, Ann Arbor, MI, USA
}

Submitted 20 December 2006: Accepted 14 June 2007: First published online 9 August 2007

\begin{abstract}
Objective: Among adults with diabetes attempting to change their own diets, we explored how these adults approached providing food for their children and how their children reacted to dietary changes in the household.

Design: The research design used semi-structured parallel individual interviews of adults and a child (aged 10-17 years) in their home. Interviews were audio-taped, transcribed, coded and analysed for themes.

Subjects: Subjects included families in which one inner-city African American or Latino adult with diabetes had completed a diabetes intervention promoting healthy dietary behaviours.

Results: We completed 29 interviews (14 adult-child pairs and one child). Adults approached making dietary changes for themselves and also providing food for their family in different ways, ranging from expecting everyone to eat the same thing to preparing two separate meals. Many children resisted dietary changes while fewer acquiesced. Among children who went along with changes, some reported resisting initially then adjusting, while others did not resist because the food still tasted good or they could obtain preferred foods outside the house. The intersection of adults' meal strategies and children's reactions to the changes can be used to categorise families into different patterns. These patterns highlight the tension between an adult who must make dietary changes to control diabetes and a child who is not necessarily motivated to change.

Conclusion: From this framework we suggest hypotheses about how these patterns might influence dietary behaviour in adults and children. Understanding these patterns could guide interventions to assist parents in successfully including children in their dietary changes.
\end{abstract}

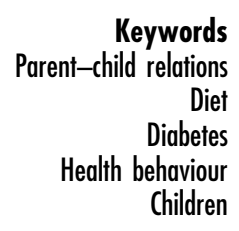

Obesity and type 2 diabetes are increasing among children due in part to poor diet habits ${ }^{1-3}$. Many dietary behaviours are learned within a family context. Parents influence children's dietary behaviours through control of access to foods, meal structure, family rules regarding food intake, modelling, children's perception of adult dietary behaviours, use of bribes and threats, and sharing of health knowledge ${ }^{4-10}$. There is still much that is not understood about the complex interaction between parents and children around food, especially with regard to teenagers and pre-teens ${ }^{11}$.
To control their disease, most adults with diabetes need to change their dietary behaviours. Such changes may challenge habitual family interactions around food. Yet adult-focused diabetes interventions and counselling often provide little or no guidance on how to make personal dietary changes while also providing food to children in the household. When adults are motivated to make changes for themselves, there may be an opportunity to help parents extend those dietary changes to their children. But first those working with parents must better understand the interactions between adults and 
children during adults' transitions to healthier dietary habits.

Since previous work has not described this phenomenon, we chose a qualitative methodology to explore the parent-child dynamics and practical issues arising in this context. Our study examines families in which one inner-city African American or Latino adult caregiver with diabetes had completed a diabetes self-management intervention promoting healthy dietary behaviours and was actively attempting to make dietary changes. We explored how these adults approached providing food for their children and how their children reacted to household dietary changes.

\section{Methods}

We followed community-based participatory research principles that emphasise community involvement throughout the research process ${ }^{12}$. We conducted qualitative, semistructured parallel interviews of adults with diabetes who had completed one year of a community-based intervention and a child in their home.

\section{The REACH intervention}

Racial and Ethnic Approaches to Community Health (REACH) Detroit Partnership, funded by the Centers for Disease Control and Prevention, is community-based intervention in inner-city Detroit aimed at improving self-management and outcomes among African American and Latino adults with type 2 diabetes. The intervention involved one year of activities, including 11 weekly twohour self-management training sessions and regular meetings with a 'family health advocate', a trained lay person acting as a case manager and lifestyle coach. Intervention messages focused on diabetes self-management, healthy diet and exercise; none included information on children. REACH participants showed a statistically and clinically significant decrease in average blood glucose (glycosolated haemoglobin: $-0.8 \%$ ) vs. a comparison group that showed no change, and reported significant dietary improvements ${ }^{13,14}$.

\section{Sampling}

To gather information-rich cases, we used purposeful sampling based on the age and sex of the child and the race/ethnicity of the family ${ }^{15-17}$. We purposefully sampled children aged 10-17 years from REACH families with a goal of recruiting at least two children (one male and one female) of each race in each age range (10-11, 12-13, 14-15, 16-17 years). We recruited families in waves to fulfil our sampling framework until all eligible families were contacted.

Inclusion criteria for children were their age (between 10 and 17 years) and living with a REACH participant for at least one year, while exclusion criteria included a diagnosis of diabetes. Adult inclusion criteria were completion of one year of REACH activities (including at least two REACH classes) and having an eligible child. Adults and children were required to speak either English or Spanish. We enrolled more 12-13-year-olds than initially planned as we found in early interviews that they expressed themselves more clearly than the younger children but were more dependent on their parents than the older children.

\section{Data collection interviews}

We conducted audio-taped, semi-structured, face-to-face interviews with children for $50-75 \mathrm{~min}$ in the child's preferred language (English or Spanish) without the adult present. Relevant domains included messages received from parents and others regarding eating, descriptions of family meals, current eating behaviours and dietary changes, and changes in family diet behaviours since the adult was diagnosed with diabetes and since completing the REACH programme (see examples in Table 1).

Adult interviews lasted 30-90 min. Relevant domains included perceptions of the child's diet; descriptions of family meals; changes in the household diet since the adult developed diabetes and since the adult started the REACH programme; how these changes affected the children; parent's perceived influence on children's eating habits; messages to children about diet, and facilitators and barriers to child diet change (see Table 1). The principal investigator (H.H.L.) conducted all Englishlanguage interviews. Trained, Masters-level, native Spanish-speaking interviewers conducted Spanish-language interviews, with the principal investigator present to add questions as she saw necessary. The study was approved by the Institutional Review Board of the University of Michigan School of Medicine.

\section{Analysis}

Interviews were audio-taped, transcribed and verified. Data were analysed and collected concurrently so insights from completed interviews could inform ongoing data collection and analysis. We analysed the interviews thematically, assisted by QSR NVivo. Our overall approach followed the 'Editing Analysis Style', which contains both deductive and inductive elements ${ }^{18}$. Deductive codes were derived from analysis frameworks based on social cognitive theory and literature review. Inductive codes were derived from the interviews to create new categories and refine framework categories.

Following this approach, two investigators independently coded transcripts and used an iterative process to compare results until agreement was reached. Other research team members read selected transcripts to compare their code interpretations with the two primary 
Table 1 Sample of questions from the semistructured interview guides

\section{Adult interviews}

1. Describe dinner last night? [Potential probes: Who was there? Did you all eat together? What did you eat? How did it compare with a usual dinner? Why are your meals set up like they are? Does the person cooking make the same meal for everyone in the family?]

2. Do you do anything special when making the children's dinner?

3. How has your diabetes changed how you take care of your health? What are the most important changes you have made? How do the children fit in?

4. How, if at all, has REACH changed how you take care of your health? How do the children fit in?

5. How have these changes in your life changed the lives of your children?

6. How much control do you have over what your children eat? [Potential probes: What are the most important things to control? How successful have you been? What ways do you use to take control? What things make that harder? What makes it easier?]

7. What do you tell your children about food?

\section{Child interviews}

1. Describe dinner last night? [Who was there? Who made dinner? What did you eat? What did everyone else eat? How did it taste?]

2. Who decides what is for dinner? [Potential probes: Do you get a say? Why/Why not? Who does the grocery shopping? Do you ask for food you want? Why/why not? Does everybody eat the same thing?]

3. What do your parents say about what you eat? [Potential probes: Are there any foods they tell you are/aren't good for you? Are there any rules about food? Does what your parents say change how you eat?]

4. Describe the last discussion you had with your parent regarding food?

5. Who has the most control or say over what you eat? How?

6. Have you changed the way you eat recently or in the past? [When? How? Why?]

7. Have other people in the family changed how they eat? [How?]

8. What changed in your day-to-day life since your____ found out s/he has diabetes? [Potential probes: Is the food different? How?]

9. How do you feel about these changes? What are the good things about these changes? Why? What are the bad things? Why?

coders. After the coding scheme was developed, the principal investigator coded all transcripts; a second researcher coded a subset to verify code reliability. All Spanish transcripts were independently coded in Spanish by a trained native Mexican-Spanish speaker and the principal investigator. Coded transcripts allowed crosscase comparison and analysis of patterns and themes. We increased the credibility of this analysis through rigorous and systematic data collection and analysis, the use of multiple readers and coders, and by documenting the reasons for analytic decisions ${ }^{19}$. All authors were involved in refining the thematic analysis and at least two team members compared the final analysis with the original transcripts.

\section{Results}

\section{Sample description}

The final sample included 29 interviews from 15 families (14 adult-child pairs and one child only) (see Table 2). Although baseline data indicated that 50 of 180 families had children between 10 and 17 years old, only 30 families were eligible: $10 \mathrm{did}$ not meet participation criteria, nine had no eligible children and one relocated. Of 30 eligible families approached for enrolment, 15 accepted, 10 declined and five could not be contacted. Fourteen of 15 adult participants were women. There were 10 parents and five grandparents. All grandparents except one were the child's primary caregiver. The other grandparent shared parenting responsibility with the child's mother but was primarily in charge of meal preparation. We use the term 'parent' to denote parent or grandparent. There were eight male and seven female children ranging from 10 to 17 years of age; seven of the 15 children were in the 12-13-year-old range and two were in the 16-17-year-old group (see Table 2). Eligible non-participants were more likely to be African American (53\% vs. 33\%), have taken fewer REACH classes (mean: 5.7 vs. 7.7) and have shown a smaller increase in fruit and vegetable consumption after the intervention. After repeated failed attempts to complete the corresponding adult interview, the single child interview was included because it added to the breadth of child perspectives on change.

The final sample included 14 motivated adults who all expressed the desire to include their children in the healthy dietary changes they were making or had made. A few adults described ambivalence about the extent of the changes they desired in their children's diets. (The results section uses the following convention: a few $=$ two or three; some $=$ four to six; half $=$ seven; a majority $=$ eight or nine; many $=10$ to 12 ; almost all $=13$ or 14 ). A majority of parents tried to decrease children's intake of candy and soda and a majority stated that they were motivated by concern about their children developing diabetes or about their child's weight (either that they were already overweight or might become overweight). One Latina mother said: 'She wants to eat all the time. And I tell her that's not right... Because she's going to get fat and then she'll get diabetes afterwards.'

Five of the 15 children described themselves in the survey portion as overweight, and two additional children 
Table 2 Characteristics of families interviewed

\begin{tabular}{|c|c|}
\hline & $\begin{array}{l}\text { Range (mean) or } \\
\text { number }\end{array}$ \\
\hline \multicolumn{2}{|l|}{ Families } \\
\hline African American & 5 \\
\hline Latino & 10 \\
\hline Number of children & $1-5$ \\
\hline Total annual family income (US $\$)^{*}$ & $\begin{array}{l}5000-10000 \text { to } \\
35000-39000\end{array}$ \\
\hline \multicolumn{2}{|l|}{ Children } \\
\hline \multicolumn{2}{|l|}{ Age } \\
\hline 10-11-year-olds & 3 \\
\hline 12-13-year-olds & 7 \\
\hline 14-15-year-olds & 3 \\
\hline 16-17-year-olds & 2 \\
\hline Male & 8 \\
\hline Female & 7 \\
\hline No. of evening meals eaten at hometł & $2-7(6.1)$ \\
\hline $\begin{array}{l}\text { No. of evening meals eaten together } \\
\text { per weekł§ }\end{array}$ & $1-7(4.9)$ \\
\hline \multicolumn{2}{|l|}{ Adults } \\
\hline Age (years) & $38-67(50)$ \\
\hline Time since REACH baseline interview & $\begin{array}{l}1 \text { year } 3 \text { months to } \\
2 \text { years } 9 \text { months }\end{array}$ \\
\hline No. of FHA contacts & $5-26(14.6)$ \\
\hline No. of classes (total 11) & $4-11(7.7)$ \\
\hline Change in total F\&V over 12 months & $\begin{array}{l}-1.1 \text { to } 9(2.45) \mathrm{F} \& \mathrm{~V} \\
\text { per day }\end{array}$ \\
\hline $\begin{array}{l}\text { Per cent consuming soda pop more } \\
\text { than once per week prior to intervention }\end{array}$ & 60 \\
\hline $\begin{array}{l}\text { Per cent consuming soda pop more } \\
\text { than once a week after intervention } §\end{array}$ & 8 \\
\hline
\end{tabular}

REACH - Racial and Ethnic Approaches to Community Health; FHA family health advocate; F\&V - fruits and vegetables.

${ }^{*}$ Out of 12 responses.

tOut of 14 responses.

¥Child report.

§Out of 13 responses.

-FHA contacts include in-person meeting and phone calls with documented in-depth interaction or documented length over $10 \mathrm{~min}$.

described themselves as the right weight but were trying to lose weight. (One of these two children in the interview described herself repeatedly as 'a little fat' and 'kind of fat' and the other said he was 'fat' but had lost some weight and was now 'big boned' and still needed to lose more weight; both had self-reported body mass index (BMI) greater than the 95th percentile.) All of these seven children appeared overweight to the interviewer (H.H.L.). No survey response was available for two children described by the interviewer (H.H.L.) as 'skinny/appropriate' and 'skinny' (this child's BMI was in the 15th percentile).

A majority of children acknowledged that their parents' dietary changes were probably also good for them, and none described the changes as unhealthy or bad for them. Although a few children accepted the changes, many children were ambivalent and a majority of children resisted changing their diets. One child airily expressed a theme common among resistant children: 'You [parent] change your diet. You're a diabetic.' Ten of the 15 children reported obtaining junk food outside the home (store, school) ranging from one large bag of candy a month to chips and soda every day.

\section{Family patterns of dietary change}

As adults tried to change their own dietary patterns, family meals became both a main venue where parents sought to influence children's diets and a battleground for conflict about those changes. Four different family patterns emerged from the interviews. Patterns were characterised by whether or not parents routinely provided alternative foods to their children and whether or not children resisted dietary changes.

- Same food: children are expected to eat the same food as the adult with diabetes and alternatives are not offered.

- Different food: if children do not want to eat the new healthier food, they are prepared alternatives or allowed to make food for themselves.

- No resistance: child and adult describe the child as going along with changes with minimal or no resistance.

- Resistance: child, adult or both describe the child as resisting changes (i.e. refusing to eat desirable food, bringing restricted food into home).

These patterns are useful analytic categories. While no one family exactly fits into one pattern at all times, each family was categorised based on their general attitude and approach towards dietary change and the children's overall response. A few families described shifting from one pattern to another over time, especially as children accepted some dietary changes.

All families varied in the extent of dietary changes made. Some changed many parts of their diet simultaneously while others focused on changing certain habits incrementally, such as decreasing soda consumption.

\section{Family Pattern 1: Same food/no or little resistance}

In Pattern 1 families (five families; see Table 3), one meal is made for everyone and the children are generally expected to eat the same food as the adult with diabetes. While in the home, children went along with most of the dietary changes.

Children in these families did not resist changes but varied in how fully they accepted them. One child (a sibling not interviewed) was described by her parent to have actively promoted dietary changes by learning and cooking new recipes. Two children expressed contentment because the food still tasted good. Two described resisting the changes initially but eventually accepting them (one as a way to help her parent). Another child went along with the changes since he ate what he wanted outside the house. Despite accepting changes at home, three of these five children said they still ate fast food, chips and soda elsewhere once to three times a week. Pattern 1 included 
one child who described him/herself as overweight, two African American families and three grandparents.

\section{Family Pattern 2: Same food/resistance}

In Pattern 2 families (three families; see Table 4), one meal is made for everyone and children are generally expected to eat the same food as the adult with diabetes but there is ongoing conflict over food. Forms of resistance included refusing certain foods, complaining, bringing home restricted foods, and sneaking other food from the kitchen. In this group and in Pattern 3 families, many children disliked the taste of 'healthy' food and were reluctant to give up foods such as chips, soda, candy and pizza. One parent described how her children accepted some changes over time, such as consuming less soft drinks or drinking lower-fat milk, but her daughter claimed that she had not changed. In another

Table 3 Same food/no or little resistance

Child enthusiastically learns to make healthier recipes

African American grandmother: My daughter, she was 16 at the time and the changes with the cooking inspired her to want to cook and it was experimenting with cooking the skinless chicken and fish and using the Mrs. Dash... She got into...experimenting with the different recipes' cause [FHA's name] would always give us two or three recipes when we came to the REACH meeting

\section{Child finds the food is still 'really good'}

Latina mother:

I: Do you think your children's nutrition is healthy?

P: Yes, because I'm the one preparing their food... I prepare vegetables... we mainly eat chicken. Either in chicken broth mixed with vegetables or just boiled with - shredded, with no fat [translation]

Her 13-year-old son: I love [dinners] 'cause she can cook really good... She knows how much to be there and how long to cook it, 'cause she knows what she can eat and what she cannot eat from her diabetes... She says she can't have like too much grease or too much not healthy food... like hamburgers or fries or stuff like that

\section{Child didn't like the changes at first but became convinced of reasons to accept them}

12-year-old girl: My grandma - she told us we had to give up candy and starches that we eat and our pop 'cause it have too much acid in there... Before when she was in the programme, I thought it wasn't going to be good - now I know that they are good changes... I thought that... it wasn't right for her to take a lot of our candy and stuff away... [I changed my mind] when my grandma told us that we could get diabetes from eating all that stuff that we ate, all that fat and grease and stuff and acid and starches

\section{Child accepts changes as a way to help parent}

15-year-old girl: [My mother] goes 'You need to change your diet'. We're like 'My diet?' and I start laughing. And I would just sit there and be like 'You can change your diet. You're a diabetic'... For a while we started doing separate meals and it just wasn't working 'cause... my mom is gonna sit there and look at the food that she wants and she's gonna look at the food she has and she's gonna want the food that she wants. So we just figured you can still cook the same food that you want but just you have to take some of the stuff out

Table 4 Same food/resistance

\section{Child concedes adult's control over food choices but seeks to resist}

Latina mother: The way I cook dinner, then, it's for everyone and that's it... I think it's a little bit difficult, because, as a grown-up, one almost doesn't accept staying this way - not eating what we are used to eating, let alone, them [the children]... Little by little, as I tell you, skim milk, something we didn't use to drink. Vegetables, I used to cook with lard and now I use oil... At the beginning they wouldn't drink the [low-fat] milk. 'No, no, I don't want it. You drink it, since you're the one that's ill'... Now, cooking with oil, they wouldn't want to eat either 'No, it tastes horrible!'... And I would answer them, 'How do you expect me to cook for myself and then again for all of you?' But, then I realised that if I ate lower [fat], then it would also be good for them

Her 12-year-old daughter:

I: Who do you think has the most control over what you eat?

R: My mom... 'Cause when I sneak in the kitchen she tells me 'Don't eat that 'cause you already ate'

I: Have you changed the way you eat in the past year?

R: No

\section{Conflict over portions, junk food and carbohydrates continues but child describes getting used to some foods}

African American grandmother: When I cook everybody's here... Maybe [granddaughter's name] will eat after I get through cooking - I'll fix her plate - she don't like it because l'm limiting her portions. But [granddaughter's name] has gained a lot of weight...l've got to do something for her - because she's not doing anything for her... l'm gonna stop her from eating all those noodles 'cause that's all carbohydrates... So she gets mad with me... She says I'm trying to control her eating. It's not that - I'm trying to keep her from getting diabetes... She eats these hot chips, and I tell her - sweetheart that is no good for you - don't you know that it's doing something to the lining of your stomach?... She eats two and three bags of 'em... She goes to the store buy 'em - she buy's 'em 'fore she get home... then she takes it and hide it in her room so I can't see it - 'cause if I see it I take it away from her

Her 13-year-old granddaughter: [Dinner is] all right. We eat like freshly cooked and stuff...

I: What do you think about how healthy food tastes?

$\mathrm{R}$ : Sometimes it tastes good and sometimes it just don't taste right because, it's like they tried to take macaroni and just take everything out I: Do you think people could get used to healthier food?

R: Uh huh - if they just keep eating it and stuff - 'cause I know I didn't use to like salad - and now I love salad... Grandma - she told me to always eat my vegetables - if I wanted to grow taller or something... So, I just said I wanted to grow taller and I started eating 'em - and I sorta got use to 'em 
family, the child said she was getting used to some vegetables but still refused eat other new foods. Pattern 2 included two children described as overweight, two African American families and one grandparent.

\section{Family Pattern 3: Different food/resistance}

In Pattern 3 families (six families; see Table 5), children resist dietary changes and parents allow the children alternatives to new food choices. When they do not like the food prepared for the adult, either children make food for themselves or some parents make children a separate or altered meal. In some families the adult with diabetes would eat a 'healthy' frozen dinner or salad while the family ate a dinner that they preferred. Whether prepared by themselves or a parent, children often chose less healthy alternatives (e.g. hotdogs, sugary cereal, ice cream and frozen meat lasagne) but occasionally ate fruit and healthier cereals.

Two families in this group expected children to decrease soda or sugar consumption. Some described gradual small changes in the children's diets as children accepted new foods.

Table 5 Different foods/resistance

Adult wants to improve child's diet but acquiesces when child resists strongly and allows child to cook other food or makes him something else (adult's poor health and fatigue also contribute)

Latina grandmother: I like to bake my stuff. And his... it's fried 'cause he loves fried porkchops and chicken and I fry it for him... He doesn't like a lot of stuff that's why it is hard for me so I just cook for me... He don't like... raw cabbage, you know like in coleslaw... I fry it sometimes or cook it in the oven, bake it or either boil it, steam it or whatever, but he doesn't like it. I just don't understand why. I guess 'cause it's my fault. I didn't make him eat that when he was younger so now wish I had

Her 13-year-old grandson:

I: Anything changed in the food?

R: For me, not really, but for her, yeah. She says she started eating more like foods that have like low calories and stuff... Well, I still like eat my stuff, yeah. Like either I don't eat at all or sometimes I eat like a hotdog or something or a cheeseburger. So yeah, that's like not changed

I: How do you get your cheeseburger?

R: Well, I cook it

Adult makes separate meals in response to resistance from children and spouse but still tries to add healthy items to their diet Latina mother:

I: You cook supper for your family and another supper for you, is that right?

R: Yes, because I cook for them. I've told my children, my family, my husband, everyone, that...I want all of us to eat what I eat, but they say, 'It's just that I don't like this.' So, then I tell them, 'It's just that I'm worried ... that you are going to go through the same thing I'm going through...' And sometimes I try to cook for them things that are nutritious, and that won't harm them, but sometimes they eat them and sometimes they don't [translation]

Adult chooses specific changes that are required for everyone (e.g. less sugar) but is still ambivalent about other dietary changes for the children (e.g. low salt and low fat) and concerned children will not eat the new food

Latina mother:

I: Are there things that have made it hard to make changes?

R: For my family, yes. Not for me. If the doctor tell me to do anything, I do it... For them I feel it's hard... because I will leave something out sometimes I believe I am - like if I do everything my way I be abusing them... like the cooking if they don't like it... So I try to keep them in the same place, you know like they eat what they like... Like, if I gotta do like rice and beans with no salt... I don't believe that is fair, because they are accustomed to it with salt... So that's why I cook my stuff on a side... then I put a little salt for them

I: What do you think is fair?

R: Cook the regular food for them, for the kids... Like put salt for them, put the grease, cook the way it's supposed to be cooked

$\mathrm{I}$ : How do you think your kids would react if you changed their food?

R: They don't eat

Her 17-year-old son: Most of the time my mom [decides what's for dinner], but every now and then we pick what we want to eat... I just hint around so she get the idea... my ma will cook whatever I say like the same day or the next day... She been trying to change how we eat like our sugar. Now she won't buy regular sugar no more. We buy Sweet'n'Low and like once or twice she cooked food and she didn't put no salt in it. So I put salt myself and then it came out tasting nasty. So I was like, 'Man, I don't want to eat this', so... she just been changing the salt

Child wants to make sure adult changes her diet but doesn't want to change her own diet

16-year-old girl: Since she has diabetes she always gets, like food that she's supposed to eat... like the healthy sugar-free stuff, but l'll just get stuff that me and my sister eat... Like I get us like cereal and milk and - TV dinners - macaroni and cheese - some type of fruit... she'll just get like low-fat stuff like... the little dinners that she eat... I don't like [that stuff], but that's what she got to eat so... I make sure she gets what she's supposed to have... I don't eat that stuff... It's not good to me

\section{Some resistant spouses also required different food at meals}

Latina mother: I have to cook for my husband. It doesn't matter how many times I give my children the same meals that I'm suppose to eat, I mean they will eat them, but often times they want to eat something different than that, and I have to cook what they want for them. [Husband's name] says, 'Cook some pork meat with chilli for me' and I say, 'Ay, that's poison for me and I don't want to eat that.' 'Then, cook it for me.' Okay, so I cook it [translation]

Health and fatigue sometimes lead parents to allow children to fend for themselves

Another Latina mother: I don't know what she [her daughter] had for dinner... Because I was sound asleep. I'm telling you, when I get home I'm tired [translation] 
Two parents indicated ambivalence towards how much change their children should be expected to make but overall believed in making changes. Ambivalent about her children eating foods low in salt and fat, a third parent decreased them in her own but not her children's diet. However, she was attempting to switch the family to diet soda and sugar substitutes.

Three families described a child trying to motivate his/ her parents to make dietary changes while resisting changes for him/herself. In two of these families, resistance from the spouse added to the need for separate meals. In contrast, another family in the same meal/no resistance group was trying to include a resistant father. However, if the father ate separately then the children ate healthier food with their mother. Finally, three different meal/resistance parents described struggling with health issues and fatigue which sometimes led them to allow children to make their own meals. In Pattern 3, three of the six children described themselves as overweight, one family was African American and one adult was a grandparent.

\section{Family Pattern 4: Different food/no resistance}

In Pattern 4 families (one family; see Table 6), the child does not resist changes but the parent is still providing different food for the children. In the only interviewed family of this type, the Latina mother made special food for herself and the father but different or modified food for everyone else. Interestingly, although the mother continued to make him separate food, the overweight child interviewed wanted to change his diet to lose weight. He described eating his parent's meals because they were healthier and had fewer calories.

\section{Discussion}

When adults with diabetes are motivated to make dietary changes for themselves, there may also be an opportunity to improve the diets of their children. In our study, adults found various ways to make personal dietary changes while providing food for their family, ranging from expecting everyone to eat the same thing to preparing separate meals. Many children resisted dietary changes but some did acquiesce. Children who went along with changes reported resisting initially then adjusting (one changed to help her parent); not resisting because the food still tasted good; or not resisting because they obtained the food they wanted elsewhere. The intersection of adults' meal strategies (expecting the children to make the same dietary changes as the adult with diabetes vs. offering separate meal options) and children's reaction to the changes (resistance or acceptance) can be used to categorise families into patterns. These patterns highlight the tension between an adult who must make dietary changes to control his/her diabetes and a child who is accustomed to certain foods and not necessarily motivated to make changes and also suggest hypotheses for future research.

We found no prior published studies of how dietary changes in chronically ill adults affect their children. However, data on families with middle-school children suggests that about a third allow teenagers to make themselves dinner and to eat dinner separate from the family ${ }^{20,21}$. Thus, while other families may also allow teenagers to avoid food they dislike, this strategy may become more pronounced in the setting of adult's dietary changes. Furthermore, our study found that the younger children and sometimes the spouse also ate something different from the parent with diabetes.

Patterns seen in our study may in part reflect the cultural/racial differences in parenting style noted in other studies. Four of five African American families were among the two same food patterns and in contrast six of the 10 Latino families were in the two different food patterns. One study suggested that Latino families practised more permissive parenting ${ }^{22}$ and another ${ }^{23}$ suggested that less acculturated Latina mothers were

Table 6 Different foods/no resistance

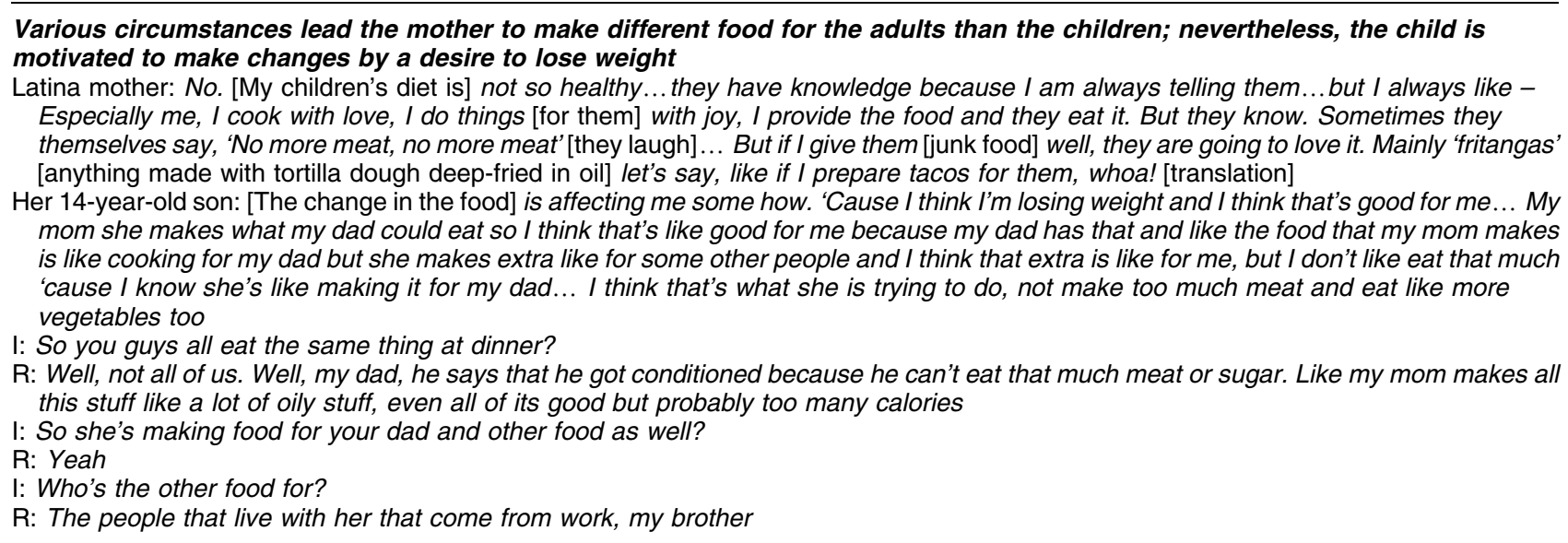


more likely to offer alternatives when a child refuses to eat. Although this was consistent with many of our Latino families, some chose a less permissive style towards diet. In addition these patterns reflect more than just feeding style, as parents' initial plans are often modified by children's reactions and other social circumstances. For example, one African American mother planned to feed everyone the same way but it became too difficult because of children's resistance, her hectic work schedule and other relatives sharing her home.

How the child's weight affected family patterns deserves further study. Although each pattern included both children who perceived themselves as overweight and normal weight, the same food/no resistance pattern included five children only one of whom was considered overweight. A review ${ }^{24}$ suggests that heavier children experience more maternal restriction and parental discouragement of eating. One could hypothesise this might increase conflict and resistance to change. On the other hand, these differences could reflect different family dynamics which also contributed to the children's weight. In general, the factors influencing parents' choice of different strategies (such as health status, response of spouse and children's reactions) warrant additional study.

Beyond describing family behaviour, this study has implications for future intervention design and evaluation. A better understanding of the significant variation in family responses to adult dietary change is crucial to designing effective dietary interventions. Motivated parents who adopted each of these strategies promoted some positive dietary change among their children, such as decreasing soda availability in the household. Interventions may enhance this positive change through tailored guidance and support. We hypothesise that for certain families it may make more sense to encourage parents to first make the needed changes for themselves and then gradually include children or give them healthier alternatives. Despite the availability to children of less healthy alternative food, families in both of the different food patterns described small changes in the children's diets over time. Parents focused on specific changes, such as limiting soda pop and cooking everyone's food with less fat. In addition some also encouraged their children to try the new food. While a potential downside to this approach is the increased burden on the meal preparer, one mother reduced this burden by using the same base items, such as meat, and changing only a portion of the meal for her children.

Other families (e.g. same food/resistance pattern) may require further study as to whether they inadvertently encourage excessive rigidity around food choices. Studies in younger children suggest that this could increase consumption in unrestricted settings ${ }^{25}$ and decrease ability to self-regulate caloric intake ${ }^{10,26}$. Furthermore, overly 'controlling' parenting has been associated with unhealthy eating among young Latina girls ${ }^{27}$. A couple of families described children hiding food and sneaking food from the kitchen. It is important to determine the prevalence, frequency and amount of such secretive behaviour among children in these families, whether it improves over time, and how to help parents adjust their strategies both to reduce this behaviour as well as the overall conflict around food. Perhaps strategies adopted from family-based child obesity treatment programmes could help instruct parents in adult lifestyle programmes in the delicate balance between too much restriction and necessary changes to help children eat healthily ${ }^{28,29}$.

This study also suggests that some families may benefit from learning to prepare appetising healthy meals and from encouragement to keep offering new foods. Consistent with other literature, taste affected children's reactions to dietary changes ${ }^{7}$. Resisting children complained about the taste of new foods and accepting children emphasised that the food still tasted good. Some children described adapting to and even liking new foods over time. This suggests that some combination of factors such as lack of unhealthy alternatives, availability of healthy foods and parental encouragement over time could lead some children to accept new healthy foods. This is consistent with studies ${ }^{30,31}$ showing that young children must try some foods five to 10 times before they will accept it, and older children may need even more exposure $^{32}$.

\section{Limitations}

Several limitations should be considered when interpreting these results. First, although we believe we reached informational redundancy on this topic, it would have been ideal to interview several more families for confirmation. Unfortunately, we exhausted the pool of eligible families. Second, the descriptions of family diet behaviours are self-reported and subject to social desirability bias. Some children seemed reluctant to criticise their parents' food choices. On the other hand, many parents candidly described the conflicts about food and their mealtime strategies. Obtaining views from an adult and a child in the same family strengthens the validity of our findings. Third, our typology is primarily based on dietary behaviour where both parent and child are present in the home. It may be less applicable to families who rarely interact around food. Fourth, our findings are based on a small group of African American and Latino families living in inner-city neighbourhoods having a member with type 2 diabetes and thus are most applicable to groups with similar characteristics. In addition, though our sample spanned the spectrum of ages 10-17 years, we had difficulty recruiting the 16-17-year-old group so the breadth of possible responses from this group may not be as well represented. On the other hand, our over-sampling of 12-13-year-olds provided greater breadth and understanding of this group and thus our 
findings may be particularly applicable to this group. Finally, BMI data were not available on some children. However, children's reports of either being overweight or trying to lose weight were consistent with the interviewer's assessments and available BMIs, and perception of being overweight may influence behaviour more than actual weight.

\section{Conclusion}

When adults with children attempt dietary changes, family eating patterns may also change. The resulting family patterns highlight the tension between an adult desiring to make dietary changes and children who are not necessarily motivated to make similar changes. Our initial exploration provides a framework from which to hypothesise how these patterns might ultimately influence dietary behaviour in families and implications for designing interventions. Understanding the variation among family responses could help adult-focused interventions and providers tailor their guidance to parents and assist parents in including their children in their dietary change.

\section{Acknowledgements}

Sources of funding: This research was support by the Robert Wood Johnson Clinical Scholars Program and by the National Institute of Child Health and Human Development (T32 HD007534 to H.H.L.). M.H. is a VA HSR\&D Career Development awardee. REACH Detroit Partnership is funded by the Centers for Disease Control and Prevention (US0/CCU417409). The authors acknowledge the generous support of the REACH Detroit Partnership Steering Committee and staff, CHASS, and the University of Michigan School of Social Work. REACH Detroit is affiliated with the Detroit-Community Academic Urban Research Center. This material is the result of work supported with resources and the use of facilities at the Iowa Veterans Affairs Medical Center. The views expressed in this article are those of the authors and do not necessarily represent the views of the Department of Veterans Affairs.

Conflict of interest declaration: The authors have no conflicts of interest to declare.

Authorship responsibilities: H.H.L., J.F., G.P. and M.H. all contributed to the research conceptualisation and design. H.H.L., J.F., M.M.D. and M.H. contributed to the analysis through development of the coding scheme and thematic interpretation of the data. H.H.L. drafted the initial manuscript and all authors critically reviewed, edited and added to the manuscript content. G.P. also assisted in research implementation. In addition, H.H.L. led the research project, conducted interviews and coded interviews.
Acknowledgements: The authors also thank Michael Anderson, family health advocates supervisor, REACH Detroit Partnership, for his help with designing and coordinating recruitment plans; Nancy Shore and Lorena deAnda for their coding of interviews; the REACH family health advocates for their input on recruitment, interview guides and community characteristics; Joel Howell MD for his guidance and manuscript editing; and Keva Anderson and Theresita Lezuch for their help with cultural interpretation.

\section{References}

1 Fagot-Campagna A, Pettitt DJ, Engelgau MM, Burrows NR, Geiss LS, Valdez R, et al. Type 2 diabetes among North American children and adolescents: an epidemiologic review and a public health perspective. Journal of Pediatrics 2000; 136: 664-72.

2 Goran MI, Ball GD, Cruz ML. Obesity and risk of type 2 diabetes and cardiovascular disease in children and adolescents. Journal of Clinical Endocrinology and Metabolism 2003; 88: 1417-27.

3 Pinhas-Hamiel O, Zeitler P. The global spread of type 2 diabetes mellitus in children and adolescents. Journal of Pediatrics 2005; 146: 693-700.

4 Feunekes GI, De Graaf C, Meyboom S, Van Staveren WA. Food choice and fat intake of adolescents and adults: associations of intakes within social networks. Preventive Medicine 1998; 27: 645-56.

5 Gibson EL, Wardle J, Watts CJ. Fruit and vegetable consumption, nutritional knowledge and beliefs in mothers and children. Appetite 1998; 31: 205-28.

6 Neumark-Sztainer D. The social environments of adolescents: associations between socioenvironmental factors and health behaviors during adolescence. Adolescent Medicine 1999; 10: 41-55.

7 Story M, Neumark-Sztainer D, French S. Individual and environmental influences on adolescent eating behaviors. Journal of the American Dietetic Association 2002; 102: $40-51$.

8 Wardle J. Parental influences on children's diets. Proceedings of the Nutrition Society 1995; 54: 747-58.

9 Olvera-Ezzell N, Power TG, Cousins JJ. Maternal socialization of children's eating habits: strategies used by obese Mexican-American mothers. Child Development 1990; 61: 395-400

10 Francis LA, Birch LL. Maternal influences on daughters' restrained eating behavior. Health Psychology 2005; 24: $548-54$

11 Baranowski T, Hearn MD. Health behavior interventions with families. In: Gochman DS, ed. Handbook of Health Behavior Research IV: Relevance for Professionals and Issues for Future Research. New York: Plenum Press, 1997; 303-23.

12 Schulz AJ, Parker EA, Israel BA, Becker AB, Maciak BJ, Hollis R. Conducting a participatory community-based survey for a community health intervention on Detroit's east side. Journal of Public Health Management and Practice 1998; 4: 10-24.

13 Feathers JT, Kieffer EC, Palmisano G, Anderson M, Sinco B, Janz N. Racial and Ethnic Approaches to Community Health (REACH) Detroit Partnership: improving diabetes-related outcomes among African-American and Latino adults. American Journal of Public Health 2005; 95: 1552-60.

14 Effect of intensive blood-glucose control with metformin on complications in overweight patients with type 2 diabetes 
(UKPDS 34). UK Prospective Diabetes Study (UKPDS) Group. Lancet 1998; 352: 854-65.

15 Patton MQ. Qualitative Research and Evaluation Methods. Thousand Oaks, CA: Sage Publication, Inc., 2002.

16 Sandelowski M. Focus on research methods: combining qualitative and quantitative sampling, data collection, and analysis techniques in mixed-method studies. Research in Nursing and Health 2000; 23: 246-55.

17 Sandelowski M. Focus on qualitative methods: sample size in qualitative research. Research in Nursing and Health 1995; 18: 179-83.

18 Crabtree BF, Miller WL. Doing Qualitative Research. Thousand Oaks, CA: Sage Publications, 1999.

19 Mason J. Qualitative Researching. London: SAGE Publications, 2002.

20 Boutelle KN, Lytle LA, Murray DM, Birnbaum AS, Story M. Perceptions of the family mealtime environment and adolescent mealtime behavior: do adults and adolescents agree? Journal of Nutrition Education 2001; 33: 128-33.

21 Boutelle KN, Birnbaum AS, Lytle LA, Murray DM, Story M. Associations between perceived family meal environment and parent intake of fruit, vegetables, and fat. Journal of Nutrition Education and Behavior 2003; 35: 24-9.

22 Cullen KW, Baranowski T, Owens E, de Moor C, Rittenberry $\mathrm{L}$, Olvera $\mathrm{N}$, et al. Ethnic differences in social correlates of diet. Health Education Research 2002; 17: 7-18.

23 Kaiser LL, Melgar-Quiñonez HR, Lamp CL, Johns MC, Harwood JO. Acculturation of Mexican-American mothers influences child feeding strategies. Journal of the American Dietetic Association 2001; 101: 542-7.
24 Faith MS, Scanlon KS, Birch LL, Francis LA, Sherry B. Parent-child feeding strategies and their relationships to child eating and weight status. Obesity Research 2004; 12: 1711-22.

25 Birch LL, Fisher JO, Davison KK. Learning to overeat: maternal use of restrictive feeding practices promotes girls' eating in the absence of hunger. American Journal of Clinical Nutrition 2003; 78: 215-20.

26 Johnson SL, Birch LL. Parents' and children's adiposity and eating style. Pediatrics 1994; 94: 653-61.

27 Arredondo EM, Elder JP, Ayala GX, Campbell N, Baquero B, Duerksen S. Is parenting style related to children's healthy eating and physical activity in Latino families? Health Education Research 2006; 21: 862-71.

28 Edwards C, Nicholls D, Croker H, Van ZS, Viner R, Wardle J. Family-based behavioural treatment of obesity: acceptability and effectiveness in the UK. European Journal of Clinical Nutrition 2006; 60: 587-92.

29 Kitzmann KM, Beech BM. Family-based interventions for pediatric obesity: methodological and conceptual challenges from family psychology. Journal of Family Psychology 2006; 20: 175-89.

30 Birch L. Development of food acceptance patterns in the first years of life. Proceedings of the Nutrition Society 1998; 57: 617-24.

31 Birch L, Fisher JO. Appetite and eating behavior in children. In: Gaull GE, ed. The Pediatric Clinics of North America: Pediatric Nutrition. Philadelphia, PA: WB Saunders, 1995; 931-53.

32 Skinner JD, Carruth BR, Wendy B, Ziegler PJ. Children's food preferences: a longitudinal analysis. Journal of the American Dietetic Association 2002; 102: 1638-47. 